Salicylic acid 4 per cent., sodium hyposulphite 8 per cent., ferric sulphate 16 per cent., boracic acid 4 per cent., sodium biborate 4 per cent., and sorlium salicylate 4 per cent., were found not to destroy vitality. The time of exposure in these experiments was two hours.

In my experiments made in Baltimore (1881), in which the blood of a rabbit recently dead from an inoculation with material containing this micrococcus was subjected to the action of the disinfecting agent for half an hour and then injected into another rabbit, I found that certain chemical argents-sodium hyposulphite and alcohol,- when mixed with the septic blood, modified its virulence without destroying the vitality of the micro-organism; and that the inoculated animal recovered after such an inoculation, and was subsequently inmune from the effects of the unattenuated virus. I believe that the experiniental evidence here referred to is the first recorded with reference to the attenuation of virus by chemical reagents. This fact is recognised by the French author Vallin, in his "Traité des Désinfectants," published in Paris in 1882 (p. 222). On the surface of agar jelly, microcoeus Pasteuri forms a slightly elevated, nearly transparent growth, and in "stick cultures" in the same material grows to a limited extent along the track of the needle, forming a nebulous line.

The results obtained by Fräkel with reference to the influence of various temperatures on the pathogenic power of this micrococcus are as follows:-In fluid media a temperature of $42^{\circ} \mathrm{C}$., maintained for two days, suffices to neutralise the virulence of the culture. The same result is obtained at a temperature of $41^{\circ}$, maintained for four or five days. Between $39.5^{\circ}$ and $40.5^{\circ}$ the virulence is no longer abolished, but is so far modified that inoculations no longer give rise, in the rabbit, exclusively to the typical condition of the blood and enlarged spleen of septicamia, but simultaneously to an intense localisation of the virus in the serous membranes of the heart and lungs. Netter has shown that rabbits which recover after receiving an injection of saliva containing this micrococcus are subsequently immune from the form of septicæmia to which it gives rise. According to this author, the saliva of convalescents from pneumonia during the first two or three weeks is less virulent than that collected at a later date, and animals inoculated with it usually recover and are subsequently immune. Fränkel also found that the micrococcus, although still present in the sputa of convalescents from pneumonia, no longer presents the same degree of virulence, and that death may occur as late as the sixth day after the inoculation is made, instead of within twenty-four to forty-eight hours, as is the case when the rusty sputum of acute pneumonia is injected.

$N^{\prime}$ umes -I first named this micro-organism "micrococcus Pasteuri" in a paper published in the American Sournal of the Medical Sciences in 1885 (Jnly). This name has generally been adopted in this country, and is used by recent English and French authors, but the German authors have not accepted it. Thus Flugge briefly describes it under the name "bacillus septicus sputigenus (Frinkel)," thus ignoring all the work which liad been done upon it prior to the time that Frinkel commenced his researches. Biondi," following Flugge's classification, calls it " hacillus salivarius septicus." Frankel speaks of it as the "micrococcus of sputum septicremia," or as the "lancet-shaped pneumonia coccus." "Weichselbaum and other Gernan authors frequently speak of it as "Fränkel's pneumonia coccus" or as the "diplococcus pneumonix." Gamaléia, recognising it as a streptococcus, as I had done previously, ${ }^{13}$ calls it "streptococcus lanceolatus Pasteuri." I do not object to this modification of the name which I felt inyself authorised to give to this much-named microbe in 1885, and which has all the rights of priority. but I do object to the designation "Fräkel's diplococcus" or "Fräkel's pneumonia coccus," which so many German writers have seen fit to apply to it. While I fully recognise the value of Frankel's contributions to our knowledge with reference to its presence in pneumonia exudate \&c., I inust insist that Talamon deserves the credit of having first produced typical lobar pneumonia in rabbits by injecting this micrococcus through the thoracic walls. We have most positive evidence of this fact in the quotation alrearly made from the work of Professor Cermain Sée, published in Paris in 1885. If, therefore, it is anyone's pneumonia coccus, it is Talamon's. And in view of the fact

I1 Zeitschrift fiir Hygiene, Bd. xi., 1887, Heft 2, p. 194

12 See my paper in the Journal of the Royal Microscopical Society, June, 1886, p. 396 . that I discovered it in 1880, photographed it, and described its morphological characters in 1881, and made extended researches relating to its physiological characters, resistance to heat, to chemical agents, $\&$ c., in 1881 to 1883 , I think I may properly object to its being called " Fränkel's diplococcns" or "Friinkel's micrococcus (or bacillus) of sputum septicremia."

Having thus briefly reviewed the history of our know. ledxe with reference to this interesting micro-organism, and shown the nature of the evidence upon which it is claimed by several competent bacteriologists to be the infectious acent in acute pneumonia, I must leave the subject for further consideration and experimental investigation.

\section{"ACTAA RACEMOSA" IN DISEASES OF NERVOUS ORIGIN.}

\section{By J. CRAIG BALFOUR, L.R.C.P. \& S. ED.}

Although the present Pharmacopoia has retained this drug under its new name of "cimicifugin," yet its value as a therapentic agent in diseases of nervous or rheumatic origin seems to be far from appreciated by most men in general practice; in fact, I have heard of one London physician making the statement that its use was now almost entirely confined to specialists. In mentioning it some years ago to a leading hospital physician, he, while admitting its value, complained of an uncertainty in its action, as he had found it fail where he expected the best results; but, having used it a good deal lately with success, I append a short statement of two or three cases, which may have the effect of inducing some to give it a trial where other remedies have failed.

The first is that of a rather nervously constituted and not very robust young lady, who had suffered for years from acute dysmenorrhoa. Menstruation had commenced at the age of twelve, and from the first was attended by great pain and discomfort. All the ordinary domestic remedies were tried without avail, and several physicians, both in London and elsewhere, were called in, without much relief being obtained; and, as one physician then attending the family said, after trying all the usual remedies unsuecessfully, that nothing more could be done, the patient had to resign herself to being confined to bed for a varying period each month, and to an amount of pain frequently so severe as to cause her to faint. Some years afterwards I accidentally became aware of her sufferings, and proposed that at least one more trial should be made, to see if it were really impossible to obtain relief. On inquiring about the symptoms, I arrived at the conclusion that the pain was mainly neuralgic (though perhaps partly due to congestion), and I therefore determined to try the actea, which appears to have a special effect in cases where the uterus and its appendages are implicated. I ordered ten minims of the tincture of cimicifugin to be taken night and morning for a few days before the menses were expected to appear, and to be continued during the whole period. I also ordered the patient to lie down, and to apply hot fomenta. tions or mustard poultices to the abdomen when the pain commenced. From the very beginning of the treatment she experienced great relief, and in a short time found that a dose or two at the commencement of each period sufficed, keeping her so free from pain that only on exceptional occasions was it necessary to lie down for a few hours, so that now the patient feels a different being, and is no longer haunted by the dread of each returning period. This is but one of several cases, but I have mentioned it on account of its sererity and intractability under other treatment.

The next case is that of a middle-aged lady, who suffered from a severe spasmodic pain in the stomach. In conjunction with obstinate dyspepsia, she had acute spasmodic seizures recurring at intervals of a few weeks, and terminating in prolonged fainting fits, sometimes alarming in their severity, as she suffered from an extremely weak heart. She had consulted several physicians both in England and abroad, and by all the pain was said to be neuralgic, and not due to any disease of the stomach; nothing, however, could be relied on to give relief but a draught prescribed for her by one of her medical attendants, containing chloric ether, hydrocyanic acid, tincture of bella- 
donna, and tincture of opium, and at times even this failed to have the desired effect. On account of the dyspepsia and the dread of eating anything she found apt to bring on an attack of the acute pain, she had for about six years subsisted mainly on toast, fish, and vegetables, and was able to take only very little of either at a time. Soon after her arrival in the city in which I was then practising, I was called in to attend her one night, when she had an unusually severe attack of the neuralgia in the stomach, which neither her draught nor mustard ponltices seemed to have much effect in relieving. At that time I gave a small hypodermic injection of tartrate of morphine at the seat of the pain. This soon gave relief, and there was no immediate return of the spasm, but only an extreme soreness throughout the whole region. She was always very weak for a considerable time after an attack of this sort, and could take nothing but a little beef-tea. However, I determined to try to combat the dyspepsia, though with but faint hopes of succeeding where so many had failed. I relied mainly on giving the stomach as little work as possible, and for this purpose I ordered her teaspoonful doses of a mixture of one part lime-water and two parts milk, administered about every twenty minutes. This was continued for some days, when the quantity was gradually increased, and I allowed in addition a raw egg well beaten up with milk and a little sherry. She also very soon took a teaspoonful night and morning of the juice carefully scraped out of a piece of raw beef, leaving all the tibre behind, and given mixed with a little fine bread-crumbs, and a pinch of pepper and salt. This treatment I often prefer to artificially digested foods, as being generally more easily obtainable and less expensive; the natural repugnance to raw meat is, as a rule, easily overcome, if it be carefully prepared and covered with bread-crumbs. After a short course of this treatment the patient felt a great craving for more solid food, to which she was gradually allowed to return, when she discovered she could eat almost anything in moderation without suffering from it. She was, however, considerably troubled with acidity, which was generally relieved by taking a few drops of dilute nitro-hydrochloric acid in a little water before meals. For some time there had been no return of the severe spasmodic pain, but that it was not entirely gone we at last discovered. However, on its first return I ordered ten minims of the tincture of cimicifugin to be given every eight hours in a little water, and continued for a few days, to be recommenced whenever there was any veturn of the pain or feeling of discomfort. This treatment was so successful that she is now quite free from any return of the severe neuralgic spasm, feels much better, and can eat almost anything. This patient suffered from a uterine thbroid, with a tendency to prolapse, which mav have something to do with the cause of the neuralgia and the success of the actiea treatment.

In another very interesting case the drucr proved of the greatest service, the more so, perhaps, as in the country it is nexu to impossible to make use of electrical and other means of diagnosing and treating nervous cases, especially when the patient lives at a considerable distance. A few months ago I was sent for to see a little girl of twelve rears old, residing about ten miles off, who was saic to be very seriously ill. On arriving at my destination, I found it was simply a labourer's cottage, but unusually neat and tidy, and I noticed at once that the child's mother had a delicate and more refined look than is generally met with in people of her class. On making inquiries about the patient, I was told that up to about six months previous to my visit she had been in apparent health, and had never suffered from any particular trouble, till one day, when she complainerl of pain in one les and arm, and of not feeling at all well. Fron this time onward she gradually became worse. She was at this period seen by a medical man, who treated her for neuralgia, but without much success. Living at some distance, he did not see her very often, and appears to have first stated that she was suffering from neuralgia, then from xhemmatism, and tinally that her spine was affected, and ordered complete rest. Ultimately, the parents, anxions to know if mothing further conld be done, called me in to give my opinion on her case. The patiert was lying on a sofa beside the fire, neatly and tastefully dressed; she was a pretty child, pale from long confinement, and with an anxious and frightened expression. On inquiring about her symptoms, I was informed that she complained of great pain in the less and down the spine; there was also considerable tenderness over the audomen. She could move her arms freely, but the legs only very slightly, and complained of pain in doing so, as well as acute pain when they were touched. She was apparently quite unable to walk or stand, did not sleep well, and complained of intense giddliness in the dark, and especially when left alone. I had her undressed, and examined the spine closely for any irregularity or trace of deformity, but found nothing, nor was there any specially painful spot; she seemed to have pain all over, and cried out if the back, legs, or abdomen were touched. After a thorough examination, I felt satisfied that the pain arose from no disease of the spine, but was probably a hysterical neuralgia. There was not much family listory to be got, but both the patient's mother and grandmother suffered from severe nervous head. aches, as clid also an elder sister. I told the mother that I believed her to be curable, and agreed to begin the treatment at home; at the same time warning them that she might have to be sent to the hospital, so as to benefit by a change of surroundings. To begin with, I ordered ten-minim doses of tincture of cimicifugin to be given every six hours, and in addition ten grains of bromide of ammonium at bedtime, and an extra dose whenever the pain became violent. I saw her again in about two days, and found that she slept much better, and that there already seemed to be traces of improvement, but she complained of increased pain and tendemess over the abdomen, especially over the lower portion. In addition to going on with her medicme, I then ordered mustard poultices to be applied over the region of the ovaries, to be continued about twice a day for two days, taking care not to wake them too strong or to injure the skin. This seemed to afford considerable relief, and she gradually improved till she could move about a little. The bromide was discontinued, as she no longer felt giddy when left in the dark. In about three weeks I ordered, in addition to the actica, a small dose of Easton's syrup at meal-times, as she seemed to require a little iron. At the end of six weeks' treatment she could walk with the aid of a stick, and appeared to be almost entirely free from pain. She was then sent away for change of air, and all medicines were discontinued. On returning home in about three months' time, she appeared to be perfectly well, and suffering neither from pain, giddiness, nor sleeplessness, though still delicate-looking from her long confinement to the house. I have warned her mother that there may be a return of the pain at the commencement of the menses, but if so, I beliere the actaa will again be successful in relieving it, as it has already converted her from helpless invalidism to a state of comparative health.

To these three cases, which were all severe ones and good tests of the efficacy of the irug, I may add one more. A lady, residing in London, who has had a large family, has, since the birth of her last child, suftered much from a severe neuralgic pain in the pubic regrion, which feels, she says, as if it were in the bones themselves. A few ten-drop doses of the tincture gave almost immediate relief. Redbourne, Lince.

\section{A \\ of}

\section{H OSPITAL PRACTICE, BRITISH AND FOREIGN.}

Nulla autem est alia pro certo noscendi via, nisi quamplurimas et mor. borum et dissectionum historias, tum aliorum tum proprias collectas habere, et inter se comparare.-Morgagni De Sed. et Caus. Morb. lib. iv. Procemium.

\section{MIDDLESEX HOSPITAL.}

\section{FOUR CASES OF HYDATID CYSTS OF THE LIYER, WITH} REMATKS.

\section{(Under the care of Mr. Henry Monnrs.)}

OpINIONs differ as to the period in growth of a hydatid cyst nost favourable for surgical interference. Erichsen ${ }^{1}$ says that surgical interference should never be undertaken until the tumour reaches such a size as to become a source of inconvenience to the patient. Murchison ${ }^{2}$ was of opinion that in all cases where a hydatid tumour is Jarge enough to be recognised during life, and is increasing in size, it is 